\title{
Evaluation of Test/Analysis Correlation Methods for Crash Applications
}

\author{
Karen H. Lyle \\ k.h.Jyle@larc.nasa.gov \\ NASA Langley Research Center, Hampton, VA \\ Lindley W. Bark \\ lindley.bark@mscsoftware.com \\ MSC.Software, Costa Mesa, CA \\ Karen E. Jackson \\ k.e.jackson@larc.nasa.gov \\ US Army Vehicle Technology Directorate, Hampton, VA
}

\begin{abstract}
A project has been initiated to improve crash test and analysis correlation. The work in this paper concentrated on the test and simulation results for a fuselage section. Two drop tests of the section were conducted. The first test was designed to excite the linear structural response for comparison with finite element modal analysis results. The second test was designed to provide data for correlation with crash simulations. An MSC.Dytran model was developed to generate nonlinear transient dynamic results. Following minor modifications, the same model was executed in MSC.Nastran to generate modal analysis results. The results presented in this paper concentrate on evaluation of correlation methodologies for crash test data and finite element simulation results.
\end{abstract}

\section{Introduction}

In the last decade significant advances have occurred in finite element simulation of crash energy management and experimental data acquisition systems. For example, full-scale crash simulations performed with nonlinear, transient dynamic, finite element codes can incorporate structural complexities such as: geometrically accurate models; human occupant models; and advanced material models to include nonlinear stress-strain behaviors, laminated composites, and material failure. Development of these detailed finite element models and analysis of the simulation results require investment in substantially skilled analysts and computer resources. However, schedule and budget constraints often force analysts to minimize efforts to analyze and correlate the results with experimental data. Often, the assessment of the correlation accuracy is based on the comparison of parameters such as crash pulse duration and peak or mean acceleration of the large masses. These parameters provide valuable information with regard to the global response of the aircraft. However, correlations of these gross parameters are insufficient to adequately evaluate structural modeling details.

Presented at the American Helicopter Society $57^{\text {th }}$ Annual Forum, Washington, D.C., May 9-11, 2001. This paper is a work of the U.S. Government and is therefore in the public domain.
The research to be presented in this paper is based on the need to better quantify the accuracy of crash simulation results generated by nonlinear, transient dynamic, finite element codes. Specifically, this paper will concentrate on an evaluation of data analysis and signal processing techniques for correlation of crash test data and finite element simulation results.

\section{Background}

Two examples of data recently acquired from full-scale crash tests at the NASA Langley Impact Dynamics Research Facility (IDRF) [1] are shown in Figures 1 and 2. The data shown in Figure 1 are vertical seat rail accelerometer responses for a modified Learfan aircraft that was crash tested on October 15, 1999. A report describing the test and details about the data is currently being prepared. Note that all acceleration responses in this paper are filtered with a SAE Channel Filter Class (CFC) 60, unless otherwise noted, as specified in SAE J211-1, Ref [2]. All four curves demonstrate a well-defined "crash pulse" with essentially a monotonically increasing and then monotonically decreasing behavior. Such curves are well suited to be defined and correlated with simulation results defined by peak acceleration, time of the peak acceleration, and acceleration pulse duration.

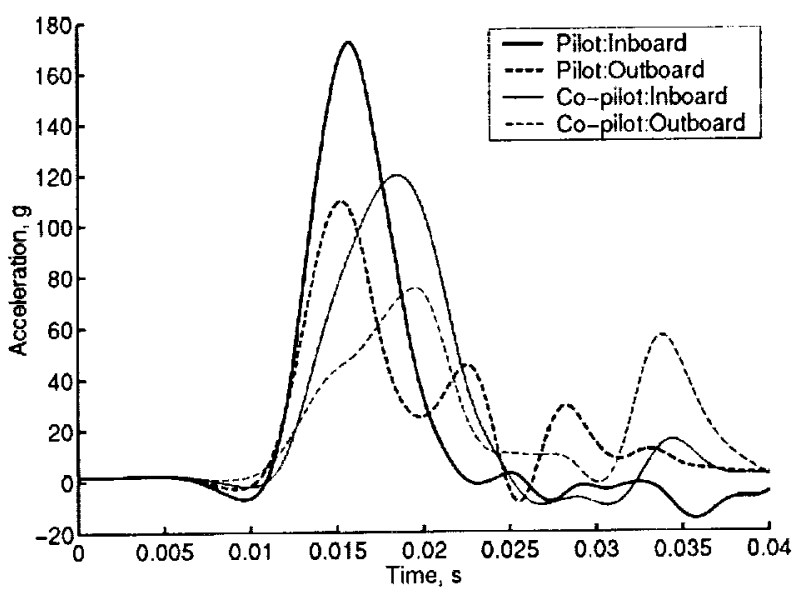

Figure 1. Sample acceleration responses for Learfan test on October 15, 1999. 
Figure 2 shows sample acceleration response data obtained from a June 22, 1999 crash test of the Sikorsky Advanced Composite Airframe Program (ACAP) helicopter, see Ref [3]. The response of the left engine exhibits a well-defined crash pulse after the fuselage contacts at $0.1 \mathrm{sec}$. The three remaining acceleration responses of the pilot and troop floor and the bulkhead show considerable oscillatory behavior. The absence of a well-defined crash pulse leads one to question whether the traditional response quantification is appropriate. Are peak acceleration, time of the peak acceleration, and crash pulse duration the appropriate correlation parameters to quantify these curves? How do current correlation practices affect these quantities? Can such curves provide sufficient information to guide designs in the future?

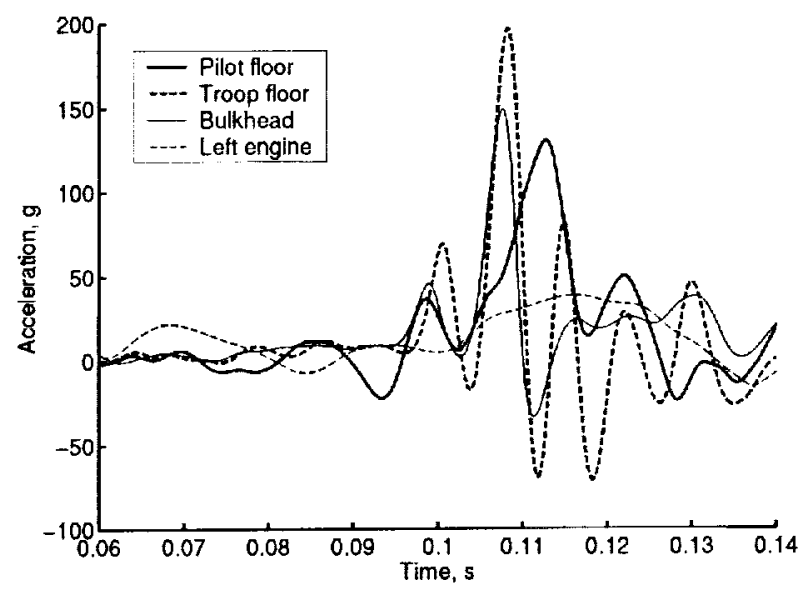

Figure 2. Sample acceleration responses acquired during the Sikorsky ACAP helicopter crash tested on June 22, 1999.

The difficulties in correlating test and analysis results are compounded by the increasing use of crash simulations utilizing detailed finite element models. The kinematic approaches developed in the 1980's use models that are generally composed of less than 100 elements (concentrated masses, beams and crush springs). Simplification of the complex structure of an aircraft to less than 100 elements requires significant engineering judgement and numerous approximations. On the other hand, these kinematic simulations enable quick computations and are well suited for early design simulations where structural details are not defined. Current modeling capabilities enable analysts to construct detailed finite element models with accurate geometric and material property information. These details allow inclusion of complex failure behavior in the material property specifications. This attention to the structural details will allow prediction of not only the large mass accelerations, but also simulation of primary and secondary structural responses.

Based on the aforementioned information, the need to re-evaluate the current crash data analysis and correlation methodologies for use with detailed finite element model simulations has been identified. A project has been initiated through the NASA Aviation Safety Program to better quantify the accuracy of crash simulation results. The motivation for the project is: to document modeling improvements; to evaluate design configurations analytically; and to enable certification by analysis. The primary objective of the project is to evaluate several methodologies, both in the time and frequency domains, for application to the correlation of crash finite element model results with measured crash data. An overview to include preliminary results for this project is contained in Ref. [4].

Two types of structural models are being employed in the evaluation of the correlation methodologies, they are: simple metallic beam and plate structures; and a representative advancedconcept, composite fuselage section. The beam and plate efforts are intended to allow evaluation of time and frequency domain analysis techniques on very simple structures. The techniques deemed viable from the simpler structural applications are then applied to the fuselage section. The fuselage section results enable evaluation of these techniques on a more realistic structure. The correlation of test and analysis for the advanced-concept, composite fuselage section is the focus of the present paper.

\section{Description of test structure}

An advanced-concept, composite full-scale fuselage aircraft section with an energy absorbing subfloor, see Figure 3 , was recently impact tested at the NASA Langley IDRF. The purpose of the test was to acquire a high quality and detailed data set for use in the test and analysis correlation project. The fuselage section was selected for several reasons. Extensive experience in both modeling and testing of the section has been gained over the past 4 years. This experience enabled the authors to concentrate on the evaluation of correlation practices rather than devote significant resources to structural design, finite element model development, and test preparation. In addition, the structure was considerably more complex than the simple metallic structures. This complexity allows the evaluation of several techniques on a more realistic structure. It should be noted that the energy absorbing fuselage section was designed for a specific floor loading and impact velocity. The floor loading and impact velocity for the data presented in this paper were selected to facilitate the evaluation of correlation methodologies. These parameters vary substantially from the original design values. Therefore the accelerations presented in this paper should not be used to evaluate the efficacy of the crashworthy design. 


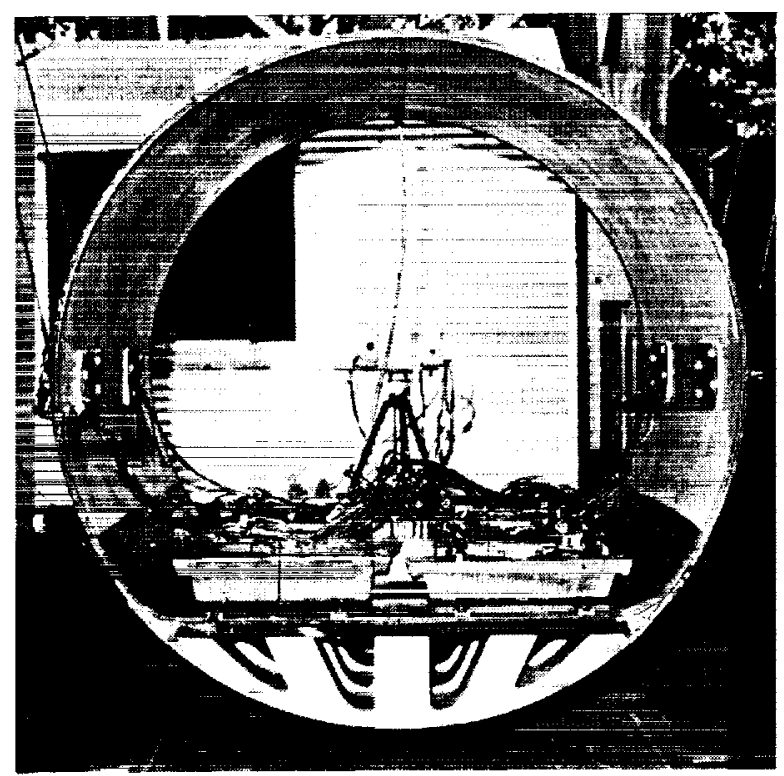

Figure 3. Photograph of fuselage section.

The fuselage section is 64 in. long with a diameter of $60 \mathrm{in}$. The design includes a very stiff floor that produces an essentially uniform global crushing of the energy absorbing subfloor. The upper section was designed to withstand typical aircraft pressurization loads and provide a protective shell for the occupants. Details regarding the fuselage section design and previous tests are documented in Ref. [5]. In the current configuration, the fuselage section contained ten 100-lb. lead weights symmetrically distributed on the fuselage floor, see Figure 4. Numerous video and high-speed film cameras as well as still cameras recorded the test. In addition, data were recorded from 73 accelerometers at $10 \mathrm{kHz}$ sampling rate by an onboard digital data acquisition system.

The accelerometers on the floor were oriented vertically. The accelerometers at Stations I, III, V, VII, and IX were located on the bolts securing the large lead masses to the aluminum seat rails. For Stations II, IV, VI, and VIII the outboard accelerometers were mounted on blocks to the seat rails. The inboard accelerometers were mounted on blocks to the data acquisition system support plates. The accelerometers positioned between the seat rails were mounted on blocks adhered directly to the floor. The accelerometers on the upper section were oriented to measure the radial acceleration, see Figure 5 and Table I. Standard crash-type accelerometers were located at three axial locations, Stations I, V, and IX. In addition, inexpensive accelerometers ( $\$ 100$ each) were located at Stations II and VIII. The inexpensive accelerometers were being evaluated for use in areas of high risk for damage or where the weight of the standard accelerometer may significantly affect the response.

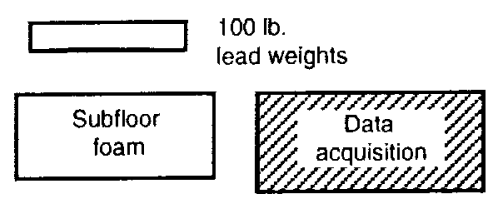

01. Position number

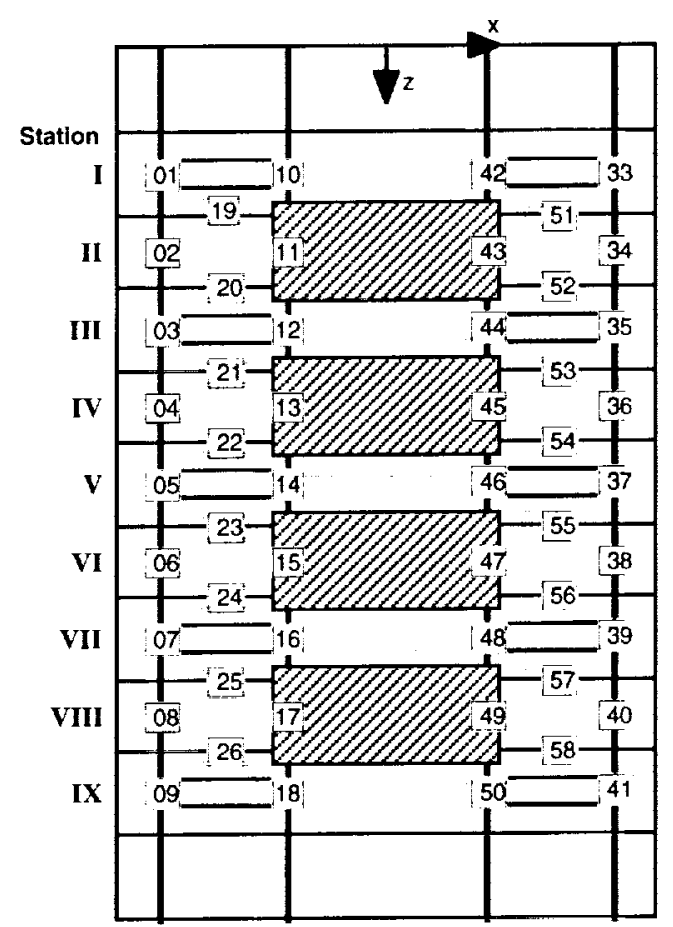

Figure 4. Top view schematic of fuselage section with instrumentation.

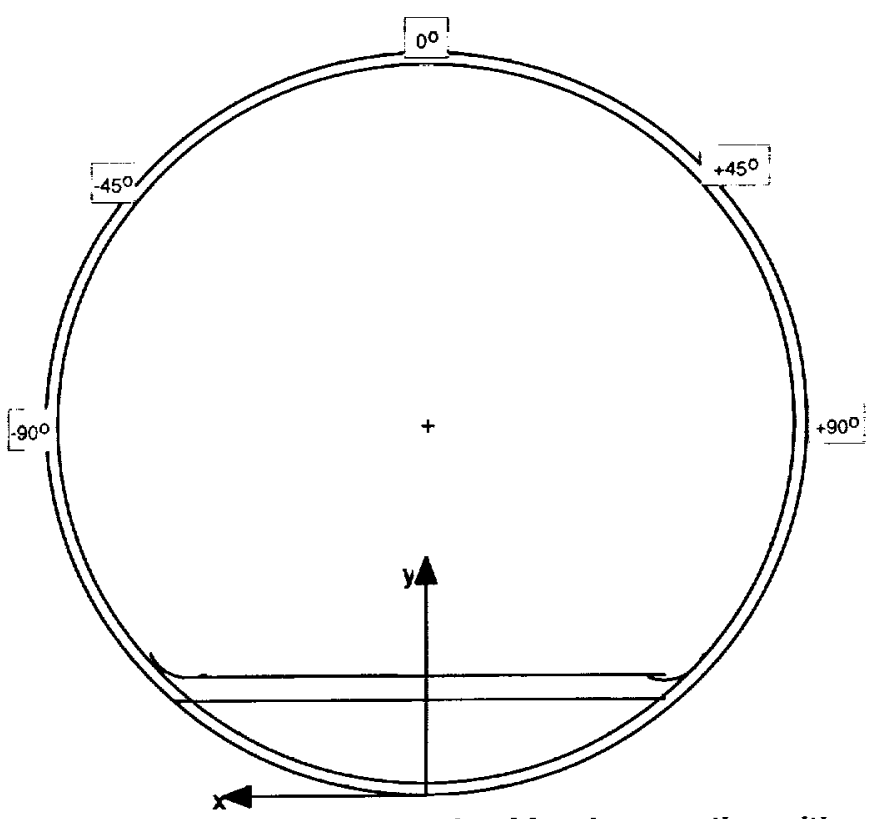

Figure 5. Front view schematic of fuselage section with instrumentation. 
Table I. Designation of position numbers for radial accelerometers.

\begin{tabular}{|c|c|c|c|c|c|}
\hline \multirow{3}{*}{ Station } & \multicolumn{5}{|c|}{ Circumferential angle, degrees } \\
\cline { 2 - 6 } & -90 & -45 & 0 & +45 & +90 \\
\hline I & 65 & 66 & 67 & 68 & 69 \\
\hline II & - & 91 & 88 & 89 & - \\
\hline V & 70 & 71 & 72 & 73 & 74 \\
\hline VIII & - & 85 & 84 & 86 & - \\
\hline IX & 75 & 76 & 77 & 78 & 79 \\
\hline
\end{tabular}

To obtain data for correlation with the finite element model, two drop tests of the fuselage section were conducted. The first test excited only the linear response of the fuselage without significant damage to the fuselage. The response for the first test will be correlated with modal analysis results generated by MSC.Nastran. The comparison of test and analysis will focus on the free vibration frequencies and relative phasing of the accelerations. The second test was designed to substantially crush the subfloor without damaging the upper portion of the section. Post-test close-up photographs of the subfloor after the 1.75-in. (37 in/sec) and 10-ft (307 in/sec) drop tests are shown in Figures 6 and 7, respectively. The 1.75-in. drop caused 0.25 -in. crush of the subfloor. This amount of crush was barely perceptible and not considered sufficient to significantly affect the fuselage response during the 10-ft drop test. No other damage to the structure was evident. The maximum crush resulting from the 10-ft drop was 3.75 in. This drop test produced no other discernable damage to structure above the subfloor.

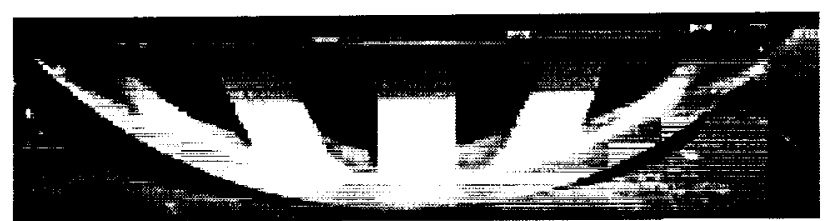

Figure 6. Photo of subfloor after 1.75-in drop.

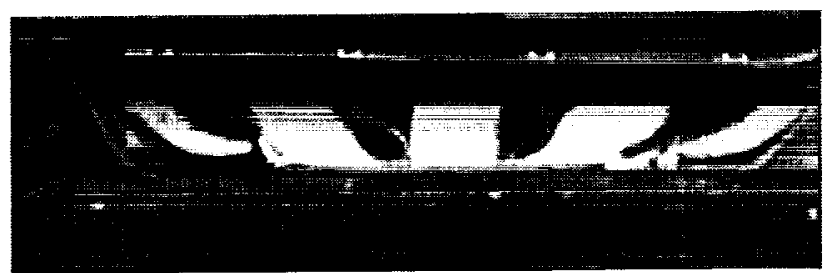

Figure 7. Photo of subfloor after 10-ft drop.

\section{Summary of test data evaluations}

Before correlating with simulation results, extensive and detailed analyses of the data from both drop tests were performed. These analyses were intended to insure that sufficient data existed to evaluate trends. In addition, the volume of data acquired proved valuable for identifying similarities and anomalies in the results. These analyses utilized the symmetry of the test structure and desired impact condition. A one-degree pitch of the section was evident in the data. Note that the predictions will be based on the a priori impact velocity from the specified drop height with no pitch or roll.

A brief summary of the data analyses will be presented in this section. Additional data evaluation results can be found in Ref. [4].

The measured accelerations of the left and right inboard seat rails at either end of the section are shown in Figure 8 . The position designations in the legend correspond to those shown in Figure 4. Although variations up to $20 \mathrm{~g}$ in the time history exist, the effect on the mean acceleration (indicated in the legend) over the first $0.050 \mathrm{sec}$ is $0.5 \mathrm{~g}$. It was difficult to equitably determine the time duration for the mean computation since the pulse duration for each position was different. The time duration does significantly affect the mean value, but has a lesser influence on the variation of the mean values. The corresponding velocities computed by numericaliy integrating the unfiltered accelerations are shown in Figure 9. A onedegree pitch attitude at impact is evident from the time delay in the onset for in both the acceleration and velocity curves.

As the data was being examined, a variety of subtle and pronounced differences between test channels was noted. Specific individual characteristics of acceleration data, e.g. peak and mean accelerations, were studied. These characteristics may individually be relatively unimportant or may be relatively important depending on the type and use of the data. It is difficult to assess the quality of correlation, as the channel-to-channel scatter of "symmetric" test data may be greater than the difference between measured and predicted results. Therefore, from a correlation standpoint, it is important to examine the characteristics of the measured and predicted results in a more systematic approach in which not only individual characteristics are examined and compared, but calculated values are compared as well. Such calculated values are designed to couple a variety of parameters, and may include consideration of factors such as duration, time over a threshold value, peak acceleration, onset rate, frequency content, and others. The present paper includes several such comparisons. 


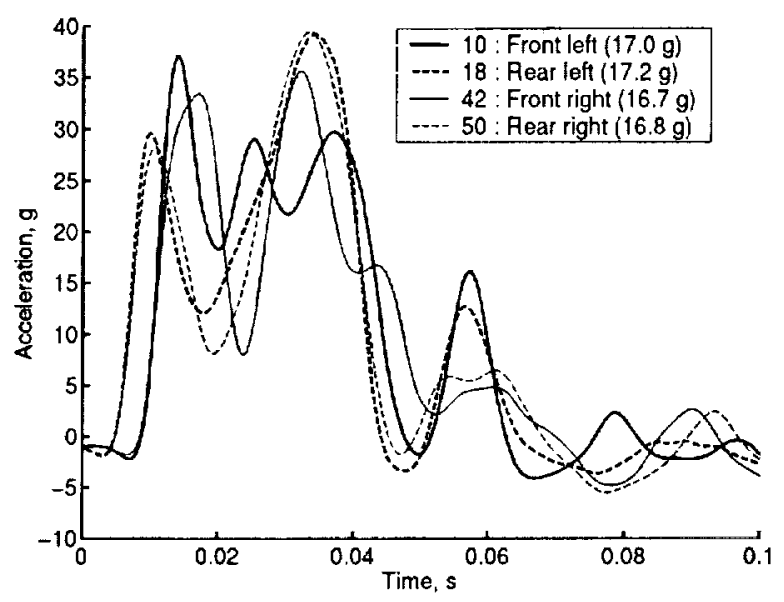

Figure 8. Comparison of the response of symmetrically located accelerometers (mean in parentheses).

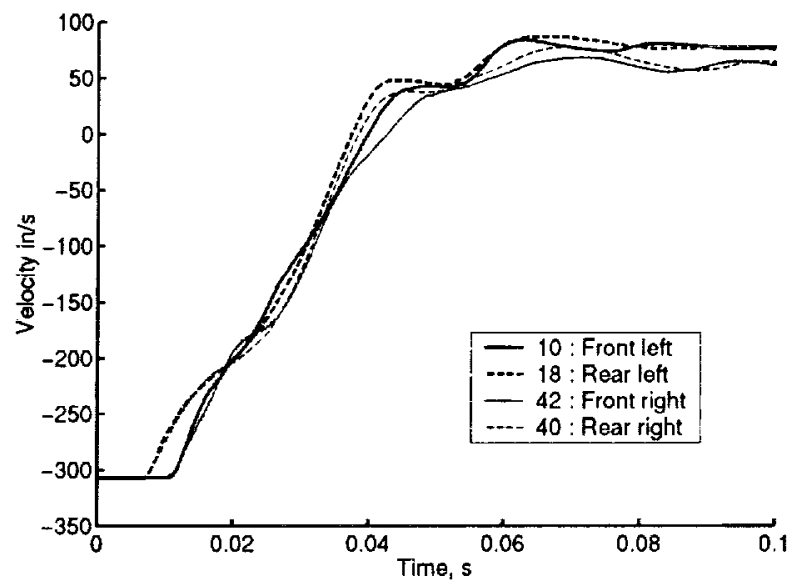

Figure 9. Comparison of the computed velocities based on the accelerometer responses in Figure 8.

At this point, results from the computation of the 1-D Dynamic Response Index (DRI), Ref [5], are presented. The computations in this paper were based on fuselage floor acceleration and, therefore, should not be compared with established human tolerance criteria. The DRI were simply calculated in order to evaluate the significance of data scatter on DRI-type computations. The 1-D DRI approximates the human response with a mass-spring-damper system. This representation is translated to a forced $2^{\text {nd }}$-order ODE where the fundamental frequency is $8.4 \mathrm{~Hz}$ and the damping is 0.224 . The DRI responses were computed from the filtered accelerations plotted in Figure 8 . The large scatter in time history values is greatly diminished when processed through the DRI, see Figure 10.

The measured accelerations and subsequent calculated results shown in Figures 8 through 10 are obtained from accelerometers mounted on the large masses. Additional questions arise as to the effect of the mass on which an accelerometer is mounted on the acceleration response. The filtered acceleration responses at three closely spaced locations (identified in Figure 4) are shown in Figure 11. Position 01 is located on a large mass mounted to the outer seat rail. Position 02 is located on a mounting block attached to the seat rail. Position 19 is located directly to the floor on a mounting block. Note that the location on the floor shows a much flatter response from .010 to $.040 \mathrm{sec}$. The scatter in mean acceleration values is $1.1 \mathrm{~g}$ for the first $0.050 \mathrm{sec}$. The corresponding velocities and DRI responses are shown in Figures 12 and 13, respectively. Although the details of the time histories vary substantially, the gross parameter comparisons show very little variation. The results verify the initial intent for the design concept where the rigid floor acts to globally crush the subfloor.

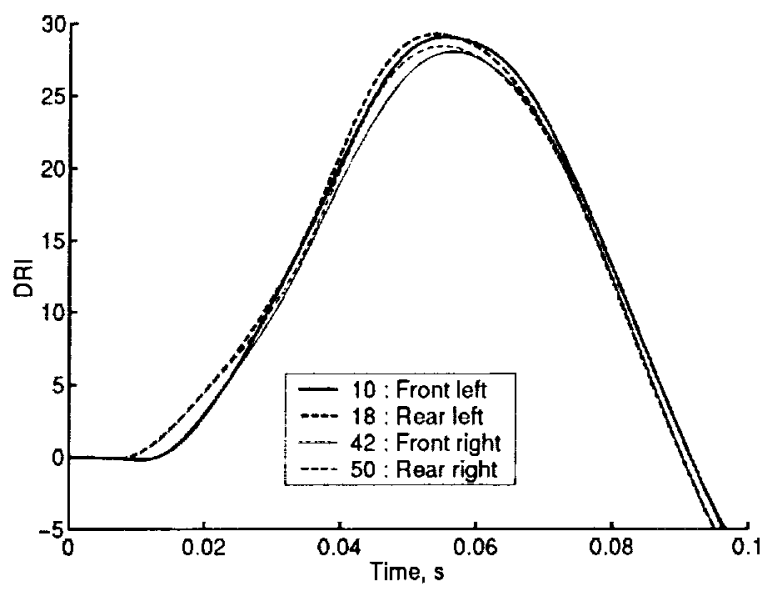

Figure 10. Computed DRI values based on the accelerometer responses In Figure 8.

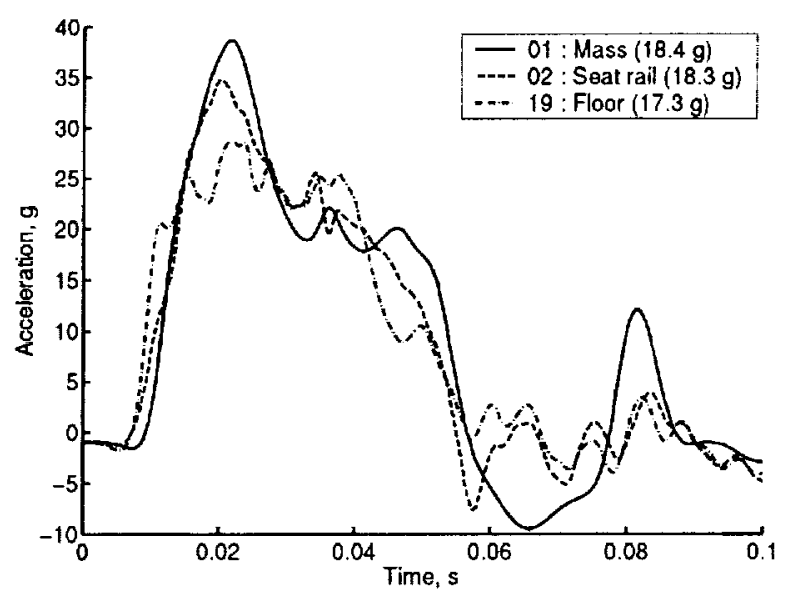

Figure 11. Effect of the mounting mass on the response of closely spaced accelerometers (mean in parenthesis). 


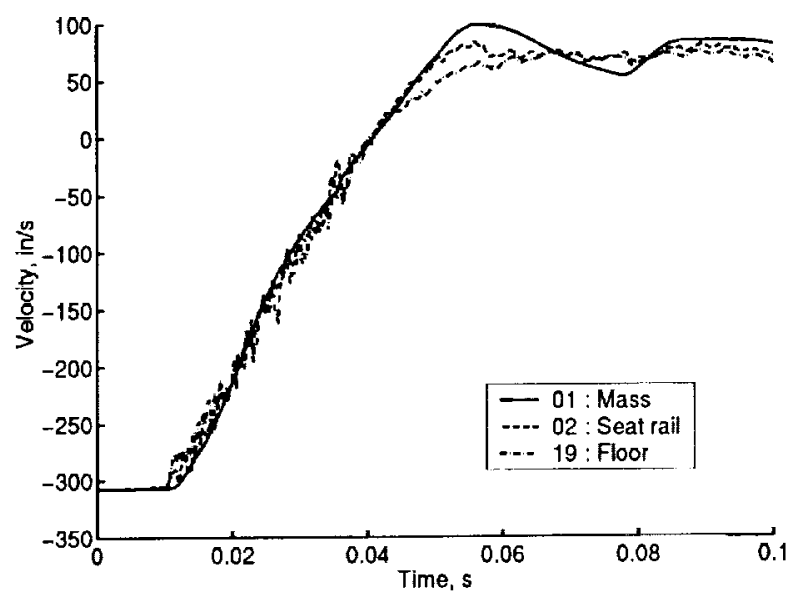

Figure 12. Effect of the mounting mass on velocity for closely spaced accelerometers.

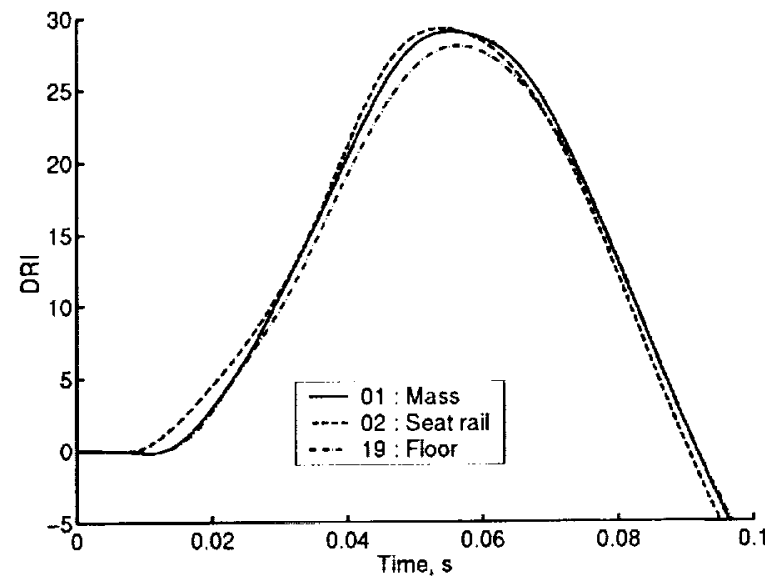

Figure 13. Effect of the mounting mass on the DRI for closely spaced accelerometers.

Finally, a comparison of acceleration responses on the upper fuselage section as measured by the inexpensive, or $\sim \$ 100$, (positions 84 and 85 ) and the standard crash-type (positions 77 and 76) accelerometers is shown in Figure 14. The accelerometer pairs at $-45^{\circ}$ (positions $76 \& 85$ ) and $0^{\circ}$ (positions $77 \& 84$ ) are axially separated by 11 in. The impact loading and attitude produced a fuselage response with very little axial variation. The pairs show a nearly identical response. The slight discrepancies are assumed to result from a combination of measurement inaccuracy and the axial separation. The availability and reliability of inexpensive and lightweight accelerometers will enable applications where: damage is probable; the effect of the accelerometer weight would significantly alter the structural response; or greater instrumentation density is needed.

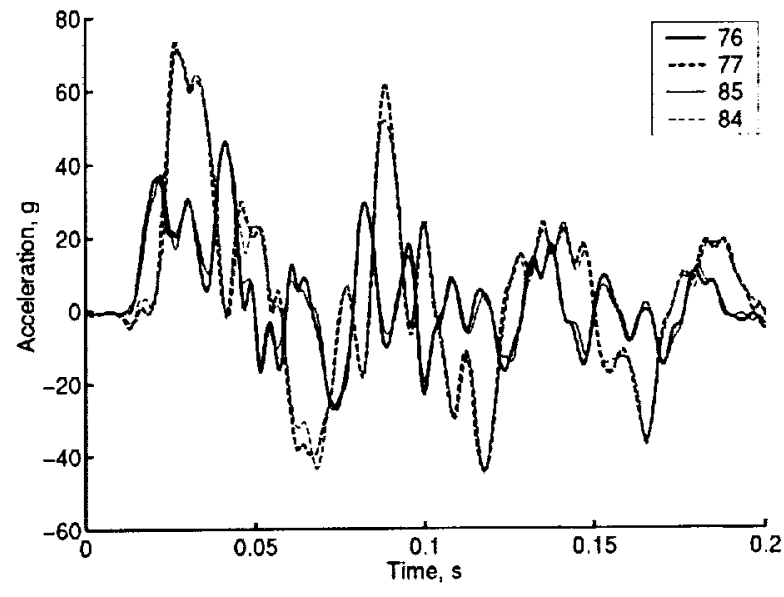

Figure 14. Comparison of accelerations for $-\$ 100(85$ and 84 ) and standard accelerometers (76 and 77 ).

Based on the findings from the extensive data evaluations, the experimental data is considered to be of sufficiently high quality to adequately evaluate, as well as to guide, the development of the correlation methodologies.

\section{Description of finite element model}

The finite element model is shown in Figure 15. The model is comprised of approximately 30,000 elements and 30,000 nodes. The rigid floor has been modeled as two laminated composite face sheets with a foam core. The foam core is represented using solid elements assigned linear elastic material properties.

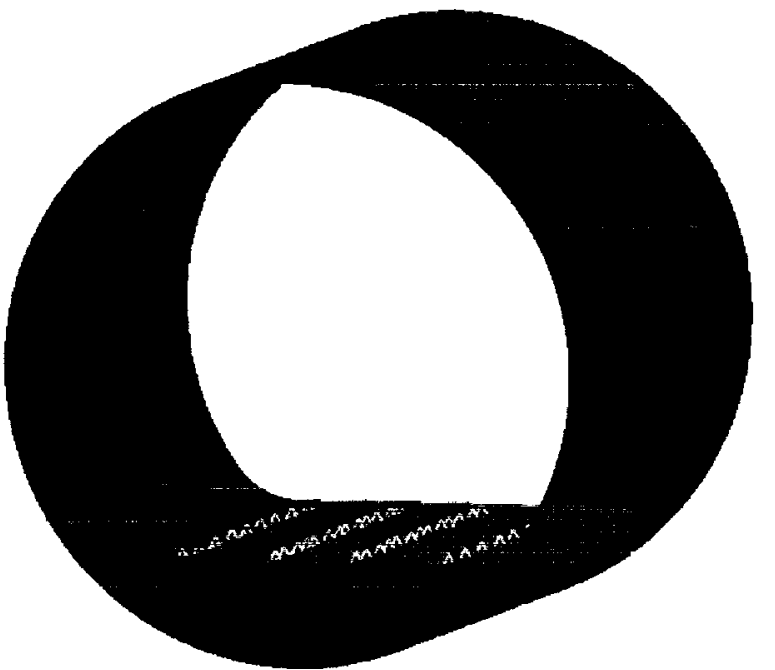

Figure 15. Schematic of fuselage finite element model.

The composite face sheets are represented with linear elastic orthotropic material properties. The upper section is also modeled with a foam core with laminated composite orthotropic face sheets. The subfloor section has solid elements with orthotropic face sheets on the interior surfaces. The accuracy of the crash simulations for this model is directly 
dependent on the accuracy of the subfloor foam material properties. A stress-strain table was supplied for the FOAM2 material properties in the model. Additional details regarding the modeling approach are found in Ref [6]. This model was used in both MSC.Nastran for modal analysis and MSC.Dytran for crash analysis.

\section{Correlation of MSC.Nastran modal results with test data}

Analytical modal analysis results are correlated with test data from the 1.75-in. drop to ascertain the accuracy of the global mass and stiffness distribution of the finite element model. The modal analysis results were generated by MSC.Nastran after converting the MSC.Dytran input file to MSC.Nastran input format. The conversion required changing the Case Control section and eliminating certain material property specifications (such as material failure) not recognized by the modal analysis solver.

To adequately evaluate the test data for comparison with modal results, several factors were considered. A summary of this information is presented in Figures 16 through 20 . First, several test data results will be presented upon which the correlations are based. Sample floor and upper structure acceleration responses for the $0.5 \mathrm{sec}$ after fuselage contact are shown in Figure 16. Note the nearly constant amplitude oscillatory behavior for the first $0.2 \mathrm{sec}$. This behavior is followed by a general decay of the structural response.

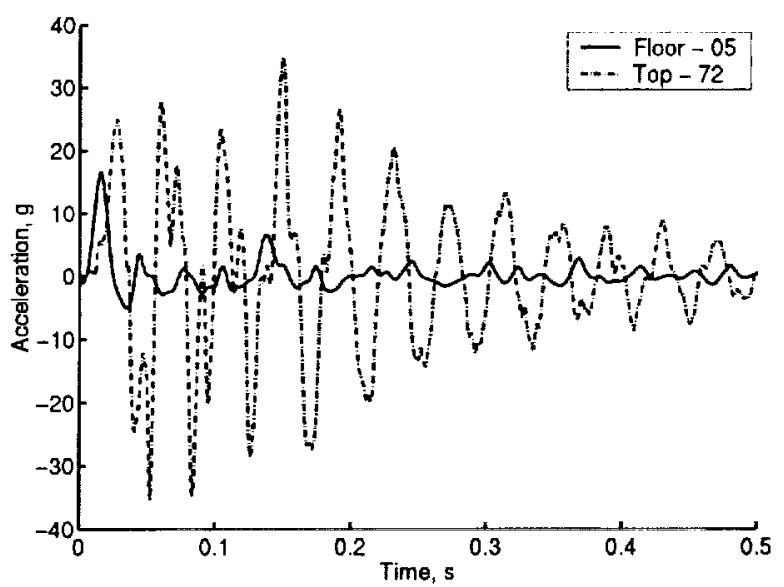

Figure 16. Experimental acceleration responses from the flexible upper structure and floor (1.75-in. drop).

Decaying acceleration responses from an outboard and an inboard floor accelerometer at Station $V$ are shown in Figure 17. The radial accelerations at Station $\mathrm{V}$ at three circumferential locations are shown in Figure 18. Note that the $-90^{\circ}$ and $0^{\circ}$ responses are similar in characteristic but out-of-phase. The response at $-45^{\circ}$ has a very different time history characteristic.

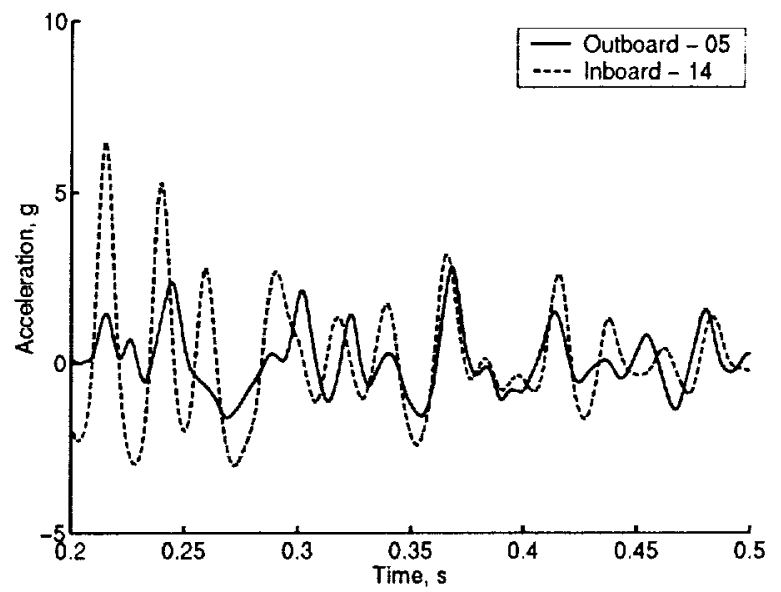

Figure 17. Decaying acceleration responses of two floor accelerometers (1.75-in. drop).

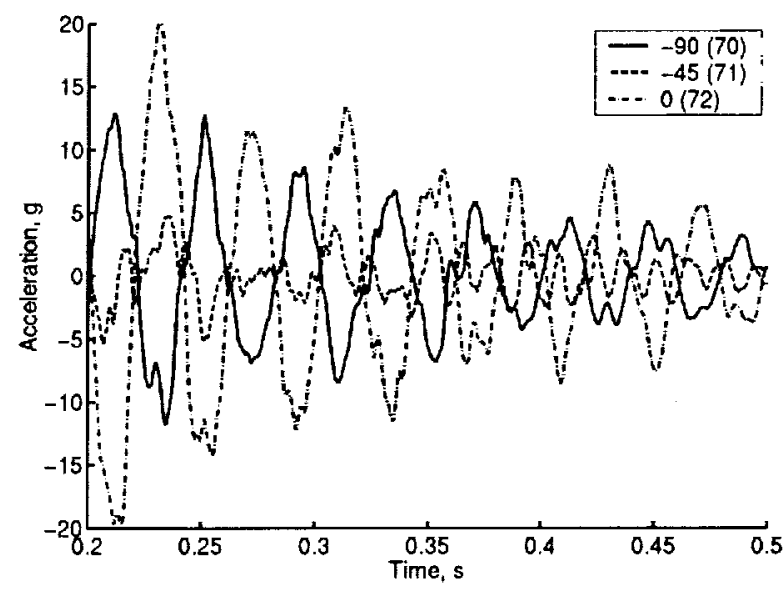

Figure 18. Decaying acceleration responses of three upper structure accelerometers (1.75-in. drop).

The measured data was further evaluated for suitability based on power spectral density (PSD), transfer function, and coherence. The reference for the transfer function and coherence computations is the response at the top of the section (position 72). All of the frequency results have been computed such that 4 averages are used with a frequency resolution of 0.3 $\mathrm{Hz}$. The normalized PSDs for the accelerometers at Station $V$ on the floor and on the upper structure are shown in the Figures 19 and 20, respectively. Each PSD curve was normalized by the respective maximum value from $0-100 \mathrm{~Hz}$, because frequencies below 100 $\mathrm{Hz}$ dominated the spectra for most positions and for consistency with the plotted filtered accelerations. Both 26 and $68 \mathrm{~Hz}$ results will be correlated with predicted modal responses. 


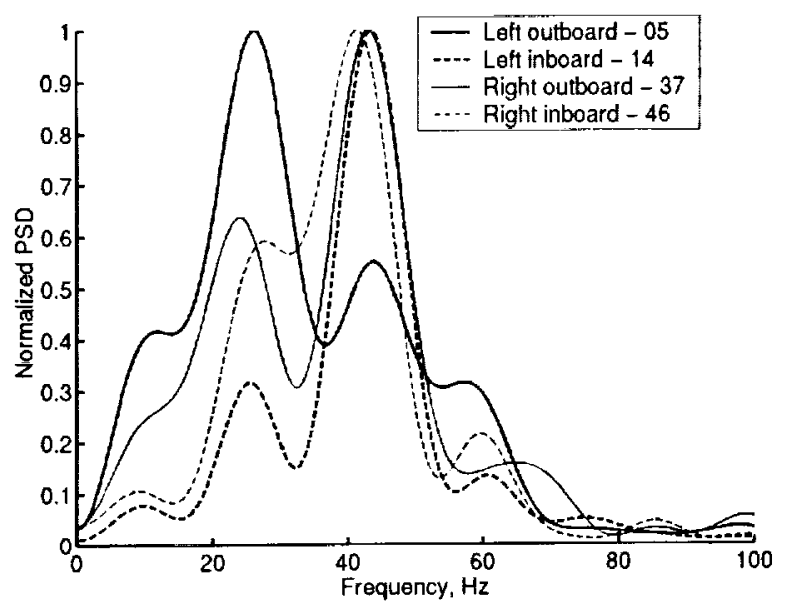

Figure 19. Normalized PSDs on the floor at Station V.

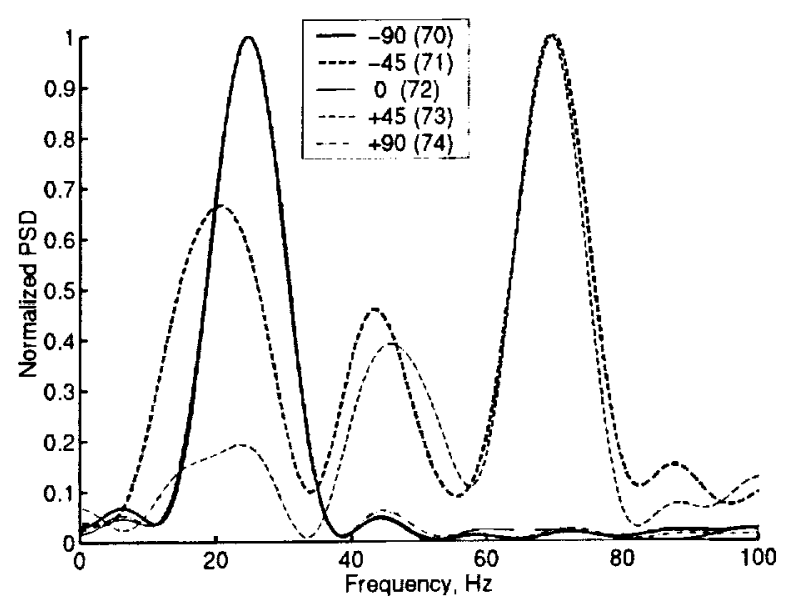

Figure 20. Normalized PSDs of upper structure locations at Station V.

Frequency domain results at $26 \mathrm{~Hz}$ as a function of position are shown in Figures 21 through 23. The coherence for $-1+90^{\circ}$, positions 70 and 74 , respectively, is nearly 1 . This result indicates that the measured response for $-1+90^{\circ}$, are linearly related to the response at the top, position 72 , with insignificant contamination from noise or multiple sources. The coherence for the outboard seat rails, positions 05 and 37 , and at $+45^{\circ}$, position 73 , on the upper structure are substantially less. The magnitude of the transfer function shows that the low coherence values could result from significantly lower signals - a difference of more that $20 \mathrm{~dB}$. This information is needed to assess the accuracy of the transfer function phase information, shown in Figure 23.

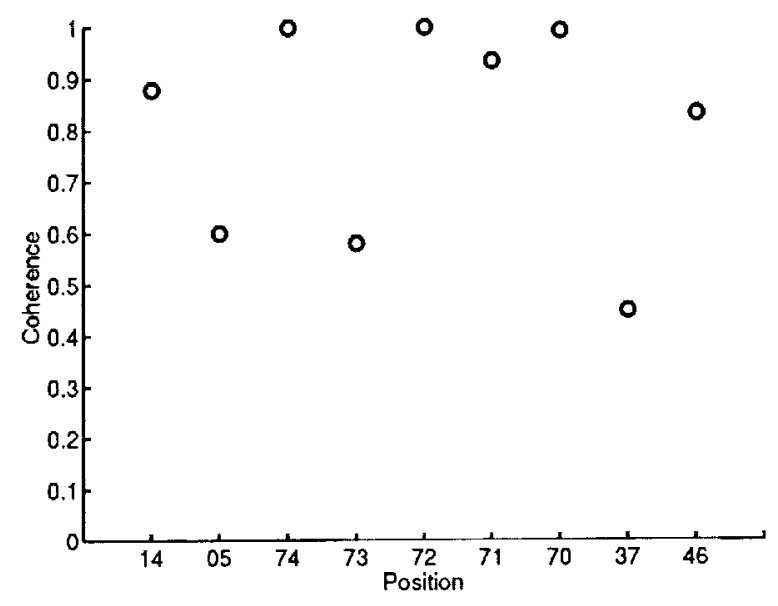

Figure 21. Coherence for $26 \mathrm{~Hz}$.

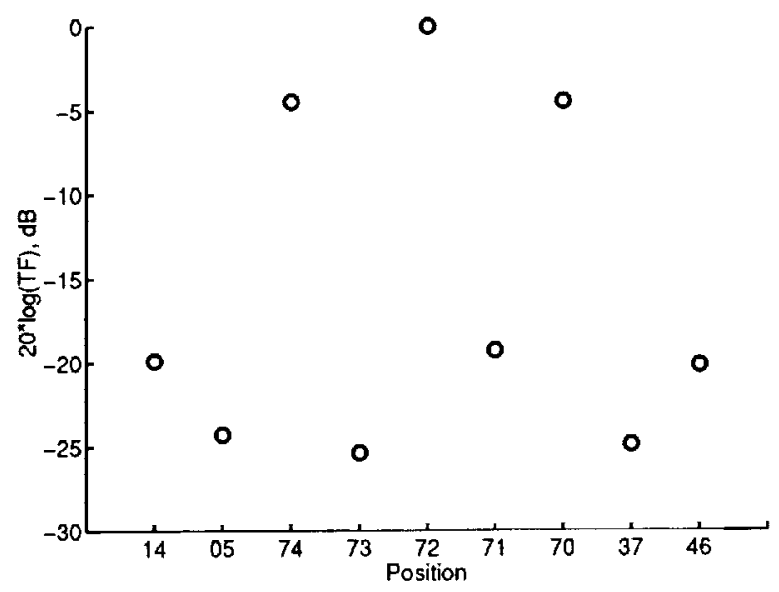

Figure 22. Magnitude of transfer function for $26 \mathrm{~Hz}$.

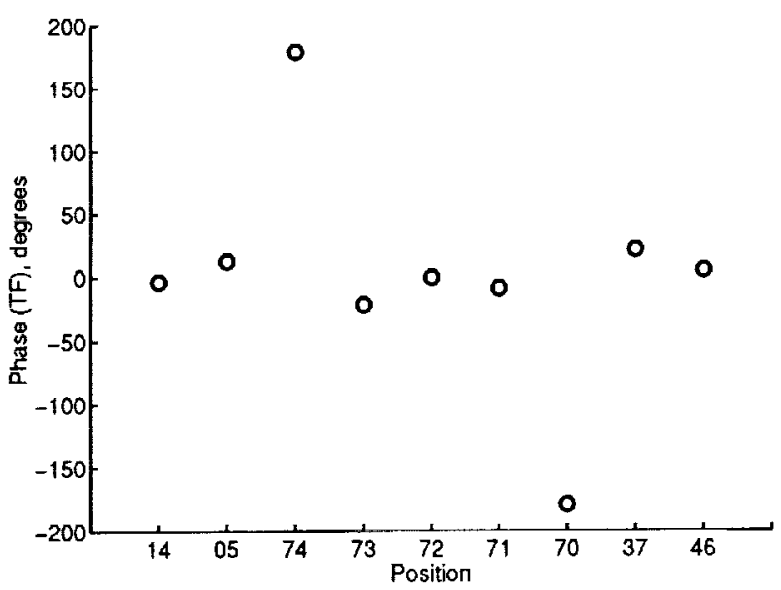

Figure 23. Phase of transfer function for $26 \mathrm{~Hz}$.

The deformed plot as generated by the analytical modal analysis is shown in Figure 24 for $26.87 \mathrm{~Hz}$ with displacement magnitude shading. The relative phasing of the deformed shape agrees with the measured phase results in Figure 23. 

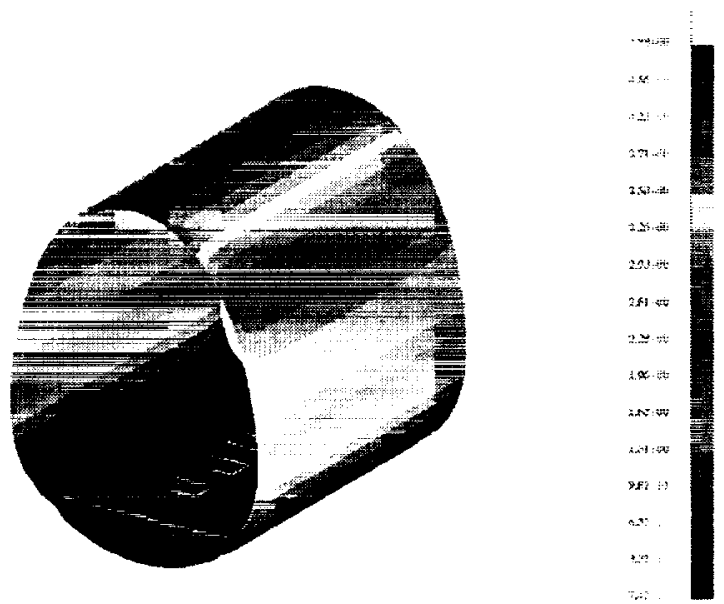

Figure 24. Analytical model shape with displacement shading $(26.87 \mathrm{~Hz})$.

Frequency domain results for $68 \mathrm{~Hz}$ as a function of position are shown in Figures 25 through 27 . The coherence for the floor locations is significantly less than 1 and in fact approaches 0 . This finding indicates that the transfer function phase results for the floor positions are not reliable. Unlike the response at $26 \mathrm{~Hz}$, the $-1+45^{\circ}$ locations (positions 71 and 73 ) are well correlated with the response at the top, position 72. The magnitudes of the responses are also very close. The magnitude of the transfer function at $-1+90^{\circ}$ (positions 70 and 74 ) is $10 \mathrm{~dB}$ less than that for position 72 . Based on the above information, the phase information for only the upper structure can be realistically compared with modal results. The phases for the floor have not been included in Figure 27 because of questionable accuracy.

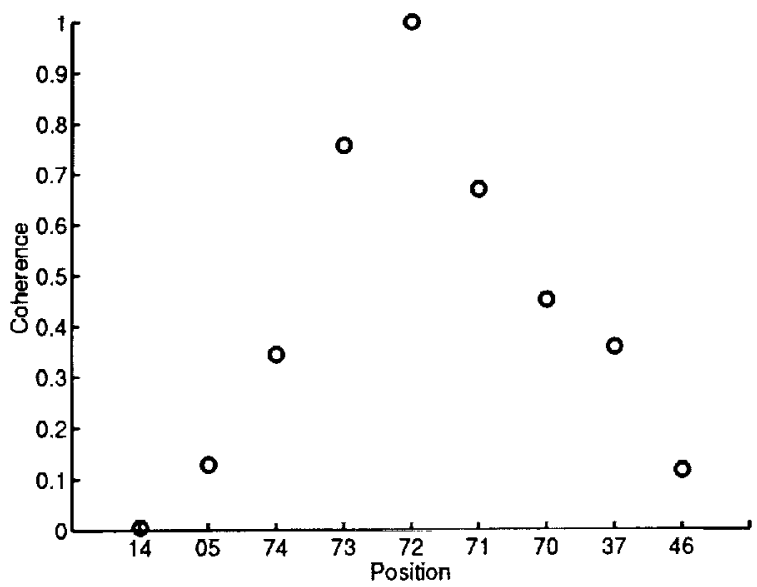

Figure 25. Coherence for $68 \mathrm{~Hz}$.

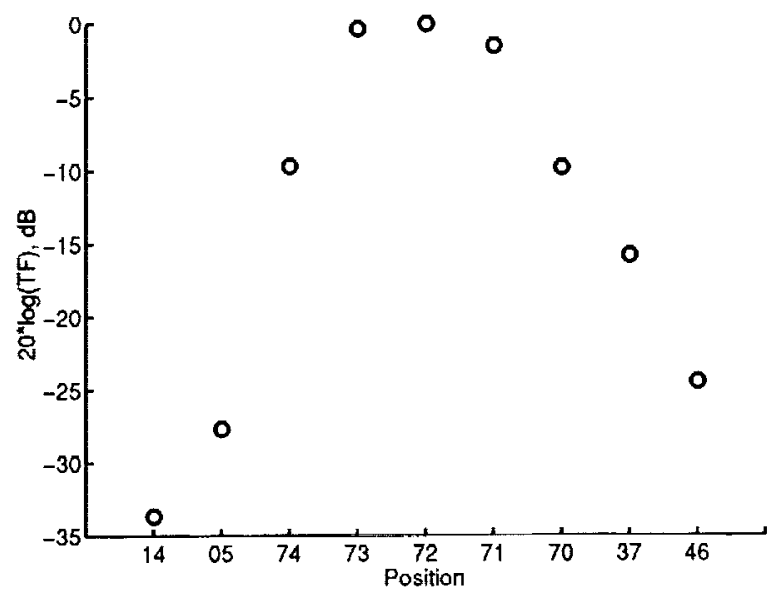

Figure 26. Magnitude of transfer function for $68 \mathrm{~Hz}$.

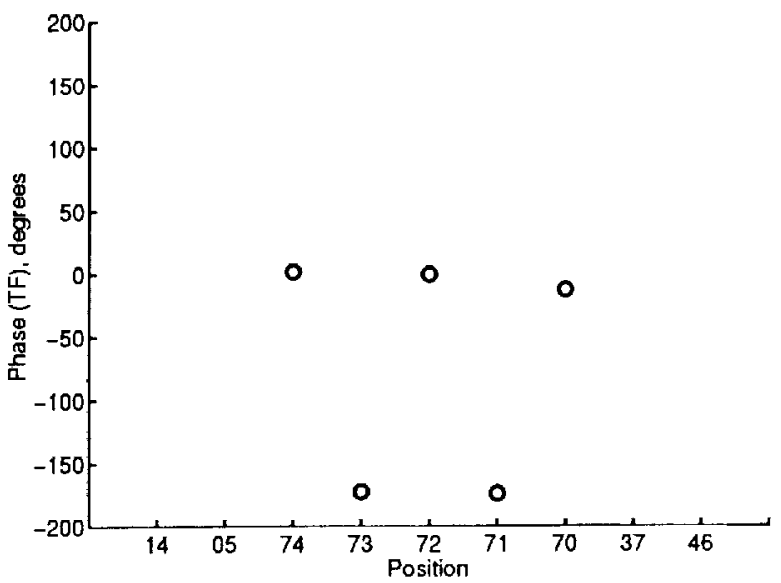

Figure 27. Phase of transfer function for $68 \mathrm{~Hz}$.

The analytical modal deformed results for $70.51 \mathrm{~Hz}$ are shown in Figure 28. As for $26 \mathrm{~Hz}$, the relative phasing of the deformed shapes of the upper structure agrees with the measured phase results, in Figure 27.
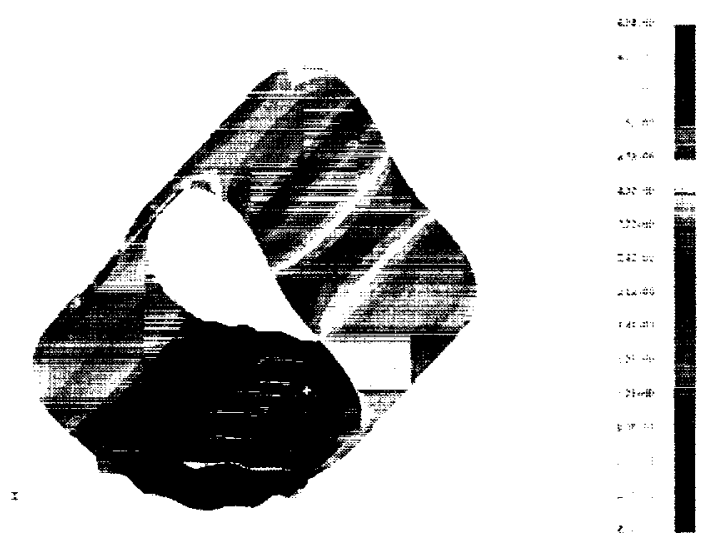

Figure 28. Analytical model shape with displacement shading $(70.51 \mathrm{~Hz})$. 
It was desired that the low drop information could be used directly for modal comparison. However, for this particular example, the upper structure dynamics are nearly uncoupled from the floor section. The symmetric impact conditions in conjunction with the fuselage section design thus reduced the information available for comparison with the predictions, as all anti-symmetric modes were repressed.

Nonetheless, the data was sufficient to evaluate the merit of the linear response and modal analysis approach for future applications. The phasing information enabled validation of the predicted mode shapes.

The measured free vibration frequency at 26 $\mathrm{Hz}$ compared well with the predicted value of $27 \mathrm{~Hz}$ while the measured value of $68 \mathrm{~Hz}$ correlated with the predicted values at $70.5 \mathrm{~Hz}$. The error in modal frequency is less than four percent. This level of accuracy indicates that the global stiffness and mass distribution for the modal analysis were well represented in the finite element model. Therefore errors in simulation and test data for the 10-ft. drop should not be attributed to global stiffness and mass distribution inaccuracies.

\section{Correlation of MSC.Dytran results with test data}

Several methods have been used to correlate the crash simulation results with the test data from the 10 -ft drop test. As for the modal response, the floor responses exhibit characteristics that are very different from those of the flexible upper section.

The measured accelerations at four symmetric inboard locations have been overplotted with the predicted accelerations, see Figure 29. The predicted acceleration curve was computed by averaging the corresponding symmetric simulation nodal results. The scatter of predicted accelerations as a function of time for the four nodes was less than $4 \mathrm{~g}$, while the variation in measured acceleration is up to $20 \mathrm{~g}$. Based on this knowledge, two concerns arose regarding: the most appropriate means to compare the test and analysis; and the significance of the variations on human response and injury. The following comparisons are an initial attempt to address these concerns.

The measured and predicted floor acceleration time histories at Station $V$ are shown in Figures 30 through 33. Note that both the measured and predicted responses show two local maxima. As stated earlier, the predictions were not altered by impact conditions to correspond with the actual test conditions in order to evaluate pre-test simulation correlation capabilities with test data. The measured and predicted outboard accelerations, see Figures 30 and 32 , have a less steep onset rate than the inboard positions, see Figures 31 and 33.
Comparisons from these figures are provided in Table II. It is interesting to note that the measured and predicted peak accelerations for 3 of the 4 curves is within $5 \%$, while at position 05 the difference is $11 \%$. The time at which the predicted peak occurs varies substantially from the measured values because of the presence of the double peak.

\begin{tabular}{|c|c|c|}
\hline \multirow{2}{*}{$\begin{array}{c}\text { Table II. Percent error In peak and time of peak } \\
\text { for four symmetric accelerometer positions. }\end{array}$} \\
\hline \multirow{3}{*}{ Position } & \multicolumn{2}{|c|}{$\%$ error } \\
\cline { 2 - 3 } & Peak & Time of peak \\
\hline 05 & 11.3 & 85.9 \\
\hline 14 & 0.1 & 18.7 \\
\hline 37 & 4.6 & 3.6 \\
\hline 46 & 3.1 & 6.6 \\
\hline
\end{tabular}

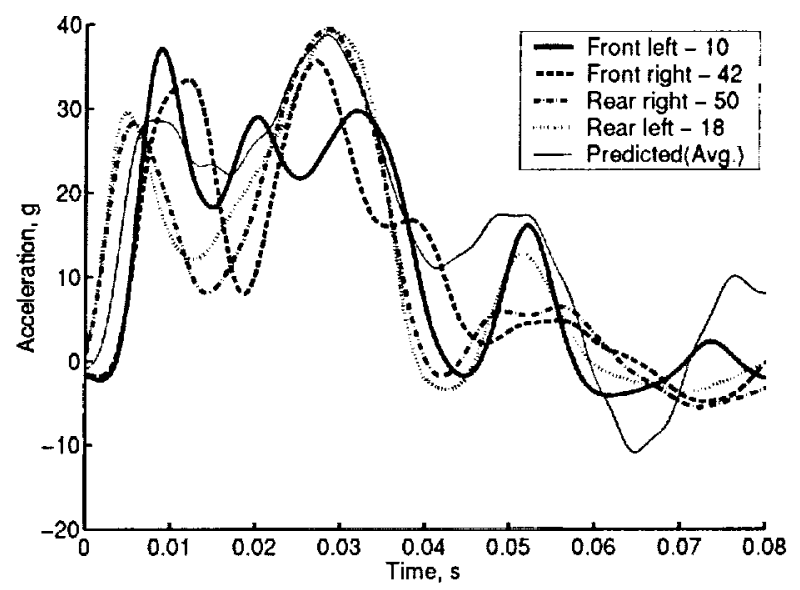

Figure 29. Measured and predicted accelerations results for symmetric positions.

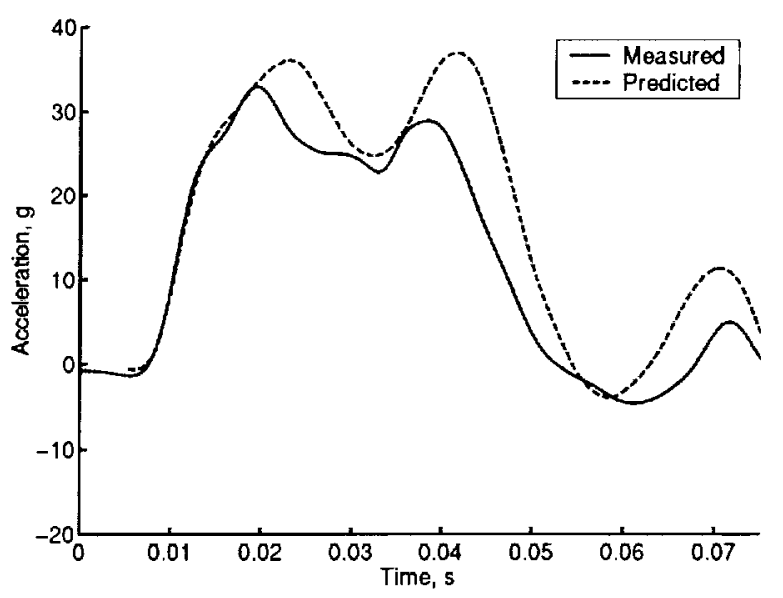

Figure 30. Left outboard measured and predicted accelerations, position 05 . 


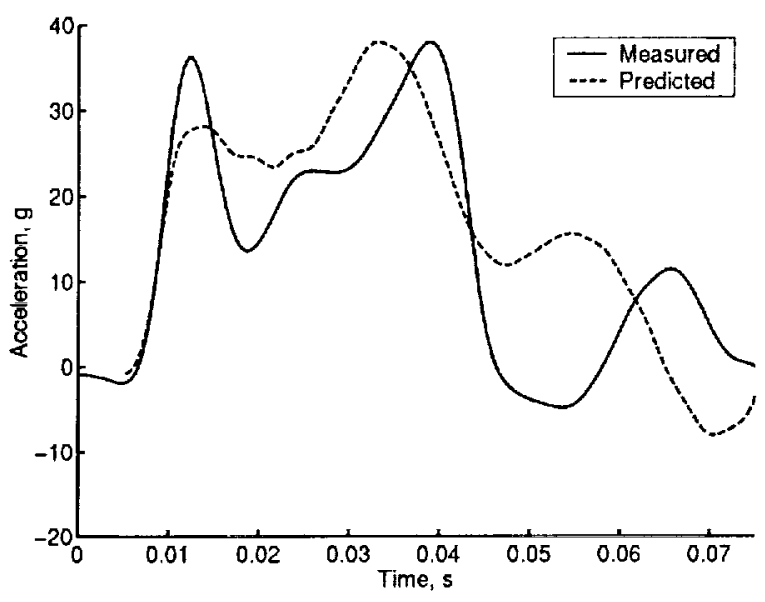

Figure 31. Left inboard measured and predicted accelerations, position 14.

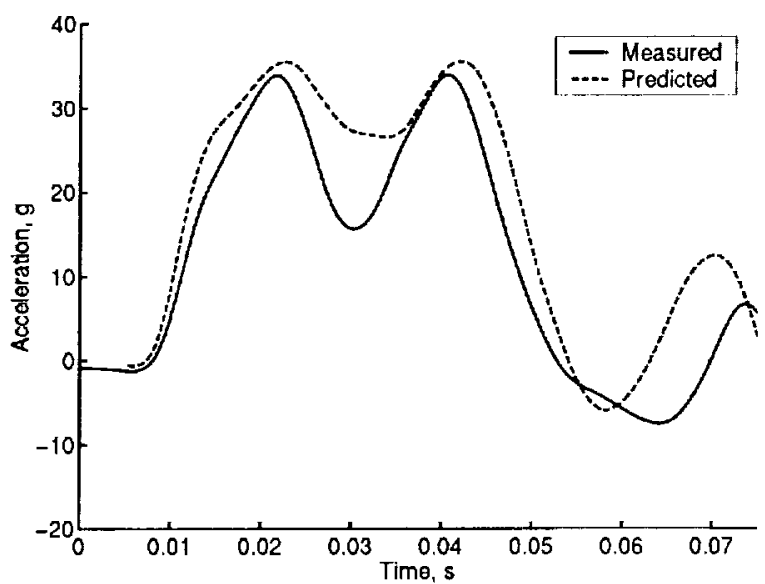

Figure 32. Right outboard measured and predicted accelerations, position 37 .

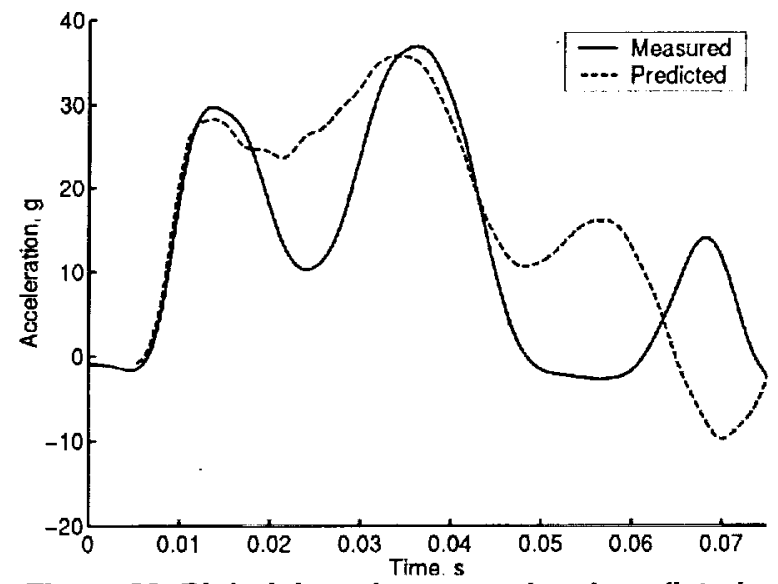

Figure 33. Right ínboard measured and predicted accelerations, position 46.

Measured and predicted radial accelerations at Station $V$ are shown in Figures 34 through 38. Unfortunately the code does not output accelerations defined by a coordinate system which moves with the structure. Therefore, the predicted results were computed by assuming a fixed orientation for the acceleration. In other words, the orientation of the predicted acceleration did not change with time with respect to the global coordinate system. This assumption appears to be valid for this particular case.

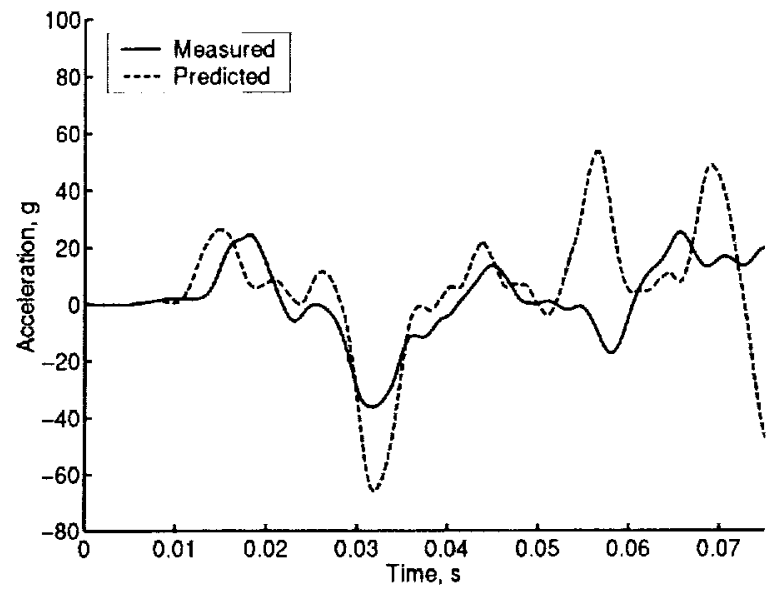

Figure 34. Left side, $-90^{\circ}$, measured and predicted radial accelerations, position $\mathbf{7 0}$.

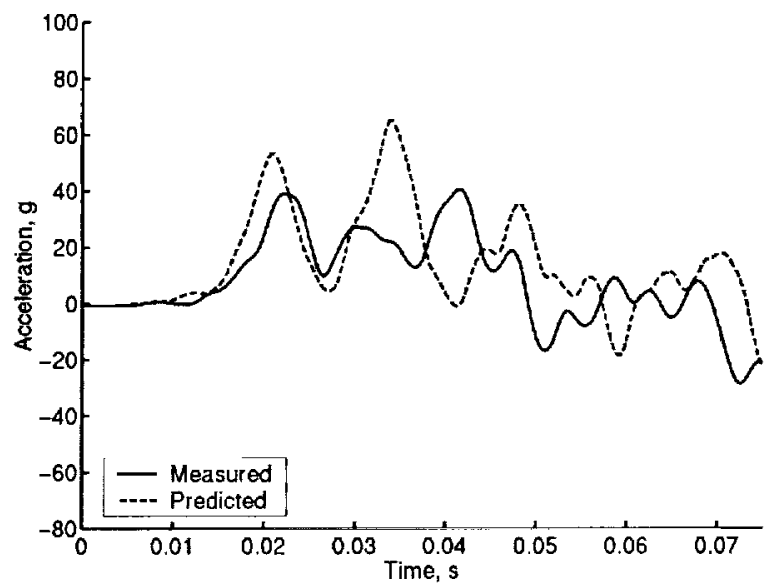

Figure 35. Left side $-45^{\circ}$, measured and predicted radial accelerations, position 71 .

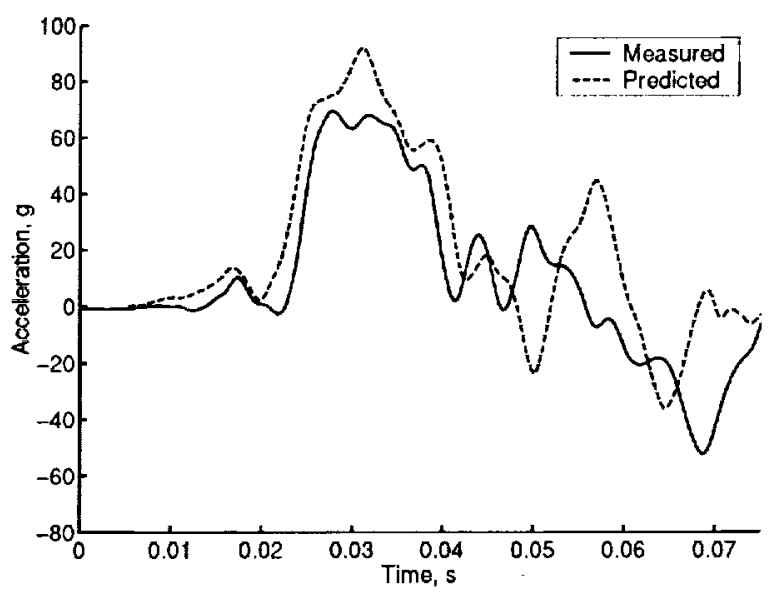

Figure 36. Top measured and predicted radial accelerations, position 72 . 


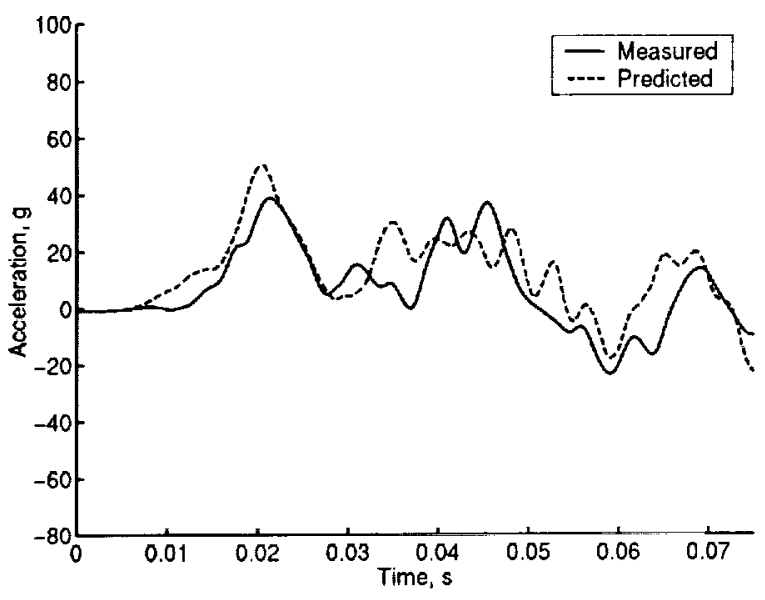

Figure 37. Right side $+45^{\circ}$, measured and predicted radial accelerations, position 73 .

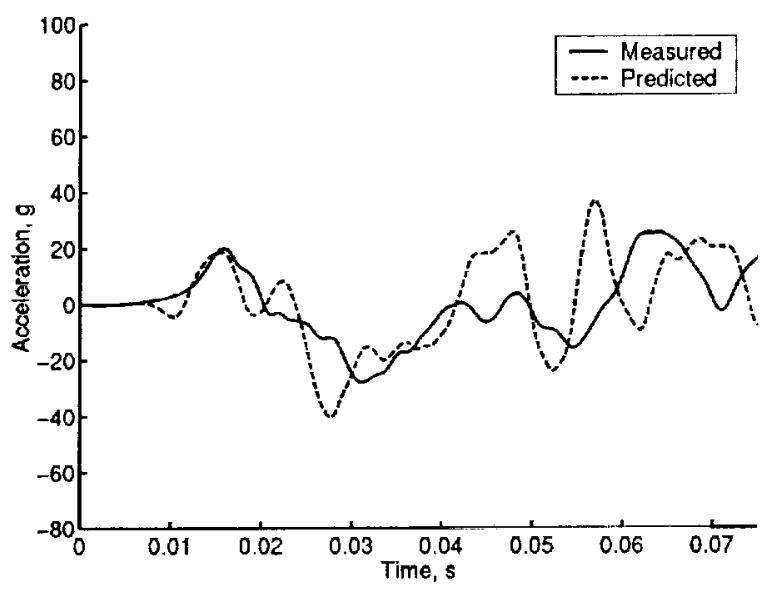

Figure 38. Right side $+90^{\circ}$, measured and predicted radial accelerations position 74 .

Note that when looking at Figures 30 through 38 , the simulation results replicate the global behavior of the measured data well. However, the comparisons highlight major concerns: 1) How to quantify this test and analysis correlation accuracy. 2) Whether the differences are significant or not. These concerns may also be more or less important depending on the type and location of the measurement.

Additional comparisons have been performed to aid in establishing the significance of the variations in accelerations for specific times. For this reason the acceleration values for test data and analysis have been processed through various data reduction methodologies including peak acceleration, DRI, and weighted-average computations in Figures 39 through 43.

The latter two comparison methods are "borrowed" from human-tolerance and injury prediction methodologies. In these cases, the investigation examines these approaches to systematically assess the suitability for application to the correlation between predicted and measured results. The approaches employed here are: to calculate the DRI, as shown earlier; and to calculate a weighted-average, which is currently based on the Head Injury Criterion (HIC). It must be absolutely stated here that these calculations are made only for a relative comparison between predicted and measured results. There is NO significance applied to the values calculated or presented with respect to tolerance thresholds. They are simply and only a means to measure closeness of different types of acceleration time histories.

For the floor location results plotted in Figures 39,41 , and 43 , the abscissa positions correspond to the front left quadrant, see Figure 4 . The remaining symmetric positions are plotted at the same abscissa location to enable evaluation of not only the prediction/test correlation but also the repeatability of the measured and predicted results.

Results in these figures do not include comparisons of data from the locations mounted on the floor between the seat rails, positions 19-26 and 51-58. The measured results were very similar in characteristic to those of the remaining floor locations, see Figure 11. The time step for the simulation was approximately 2 microseconds with data stored every 100 microseconds, which corresponds with the measured data acquisition rate. This setting caused substantial "aliasing-type" errors in the accelerations due to the very high magnitude and high frequency oscillations. Correlation of the predicted acceleration values with the measured data would therefore be meaningless. Several approaches to rectify the problem are currently under investigation. These include the inclusion of additional mass at the nodes, output of the results at every time step as well as implementation of an anti-aliasing filter on the predicted results. The pros and cons of each approach must be carefully scrutinized.

For Figures 40 and 42 , the three axial accelerometers at each specific circumferential location are plotted. At $-90^{\circ}$ only 2 measured points are included because the measured data overranged the accelerometer. The inexpensive accelerometer data has not been included.

In Figure 39, the scatter of measured peak accelerations for essentially similar locations ranges from $3.6 \mathrm{~g}$ at position 02 to $7.4 \mathrm{~g}$ at position 11 . The scatter in predicted values ranges from $0.8 \mathrm{~g}$ at position 01 to $5.1 \mathrm{~g}$ at position 13. The mean of the peak values has also been plotted. The difference in mean peak value ranges from $0.8 \mathrm{~g}$ to $6.1 \mathrm{~g}$.

The corresponding peak accelerations for the upper structure are shown in Figure 40 . The scatter in data at the circumferential position results from the 
low-frequency oscillatory nature of the response as evident in Figures 34 through 38.

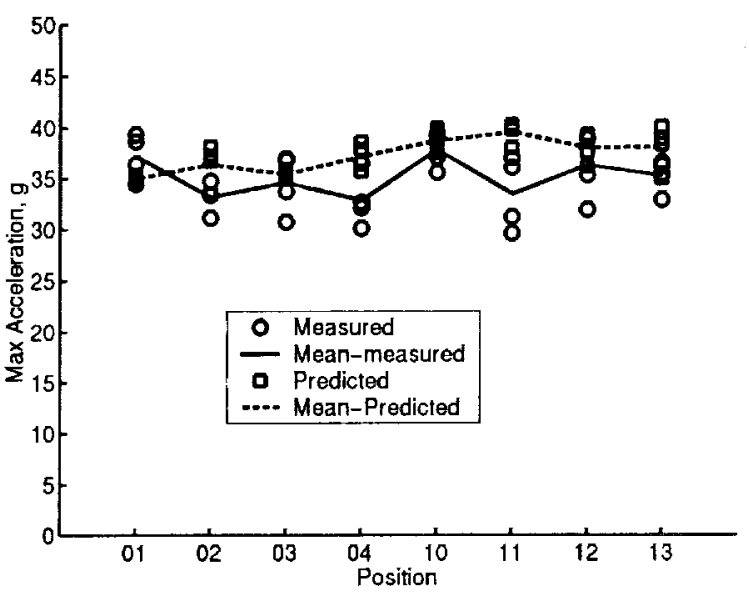

Figure 39. Measured and predicted floor maximum accelerations (Positions: Outboard 010203 04: Inboard 101112 13: Mass 010310 12: Seat rail 020411 13).

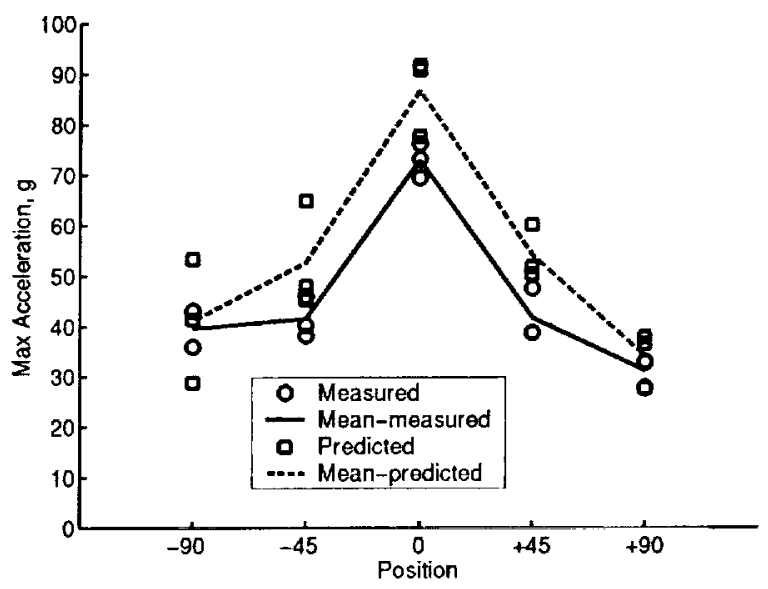

Figure 40. Measured and predicted upper structure maximum accelerations.

A second method for evaluating the correlations between test and analysis results was to process the filtered accelerations through the DRI model, see Figures 41 and 42. As shown in the data analysis section, the DRI computation greatly smoothes oscillatory behavior. These computations for the positions on the floor, Figure 41 , indicate that the large variations in time histories are nearly insignificant for the DRI, which acts like an $8.4 \mathrm{~Hz}$ filter. Unlike peak acceleration, the DRI computation clearly delineated the measured and predicted results such that the difference in mean DRI curves are nearly constant at 8 . The maximum DRI values for the upper section, see Figure 42, show large scatter for the measured and predicted values, with similar trends in the mean curves.

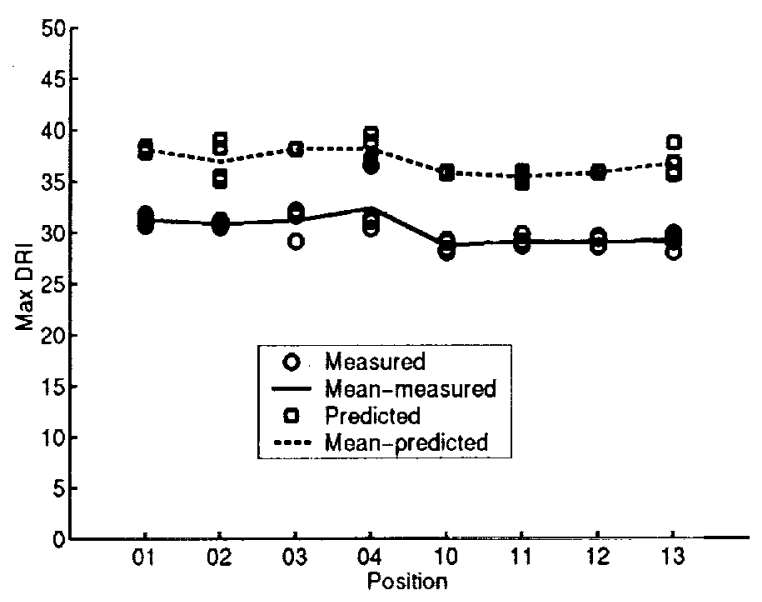

Figure 41. Measured and predicted maximum DRI values on the floor (Positions: Outboard 010203 04: Inboard 10 1112 13: Mass 010310 12: Seat rall 020411 13).

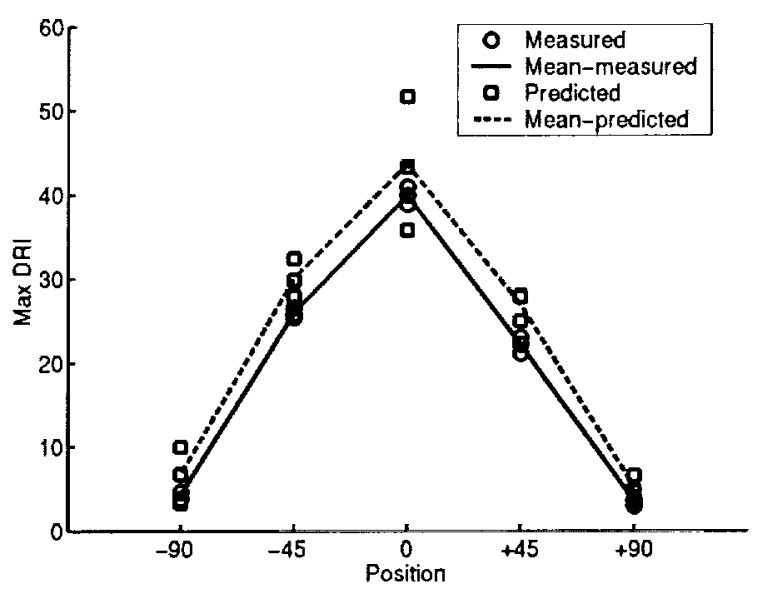

Figure 42. Measured and predicted maximum DRI values for the upper structure.

The computed weighted-average results (based on the HIC parameters) for the floor locations are shown in Figure 43. The data in the figure was based on acceleration curves filtered with a CFC 60 . As for the DRI, a distinct variation is evident in measured and predicted values where the difference in mean value ranges from 38 to 68 .

The effect of the SAE filter class on the weighted-average computation is shown in Table III. All of the positions are on the left outboard seat rail. The data with a white background are for positions on the large masses, whereas the gray background values correspond to seat rail positions. Note that with a CFC of 60 , the effect of mounting mass is small such that the scatter for the measured values is $14 \%$ and the predicted scatter is $8.3 \%$. The percent difference between measured and predicted values is $48 \%$. When the filter frequency is increased an order of magnitude to CFC 1000 , both the measured and predicted values increase substantially for the seat rail locations with 
minimal changes for the large masses. For the measured data the scatter at the large masses is $8.7 \%$, while that for the predicted results is $3.9 \%$. The scatter at the seat rails is $43 \%$ for the measured data and $39 \%$ for the predicted results. The percent error between measured and predicted results when separating the mass and seat rail data is $45 \%$ and $175 \%$, respectively.

The evaluations of the correlation procedures presented in this paper are not measured by the percent error between experimental and analytical results. Rather, the evaluation of correlation procedures are based on whether the method can delineate differences between measured and predicted results that could produce structural deterioration or human injury.

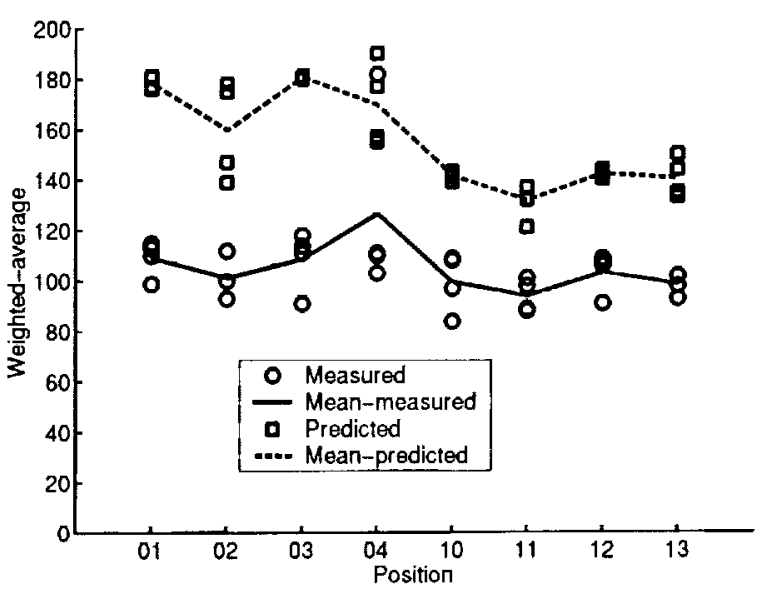

Figure 43. Correlation of measured and predicted maximum weighted-average values for the floor positions (Positions: Outboard 010203 04: Inboard 10 11 12 13: Mass 010310 12: Seat rail 020411 13).

\begin{tabular}{|c|c|c|c|c|}
\hline \multicolumn{6}{|c|}{ Table III. Effect of filtering frequency on weighted- } \\
average. \\
\hline Position & $\begin{array}{c}\text { Measured } \\
\text { (CFC 60) }\end{array}$ & $\begin{array}{c}\text { Predicted } \\
\text { (CFC 60) }\end{array}$ & $\begin{array}{c}\text { Measured } \\
\text { (CFC 1000) }\end{array}$ & $\begin{array}{c}\text { Predicted } \\
\text { (CFC 1000) }\end{array}$ \\
\hline \hline 01 & 110 & 176 & 112 & 176 \\
\hline 02 & 100 & 178 & 576 & 7107 \\
\hline 03 & 111 & 181 & 112 & 181 \\
\hline 04 & 111 & 190 & 453 & 8536 \\
\hline 05 & 112 & 183 & 114 & 183 \\
\hline 06 & 110 & 177 & 376 & 5810 \\
\hline 07 & 114 & 181 & 114 & 181 \\
\hline 08 & 112 & 175 & 470 & 6459 \\
\hline 09 & 115 & 181 & 122 & 182 \\
\hline
\end{tabular}

\section{Concluding Remarks}

This paper described an activity to better quantify the accuracy of crash test and analysis correlation. The work in this paper concentrated on the test and simulation results for an advanced-concept, full-scale fuselage section. Two drop tests of the section were conducted. The first test was designed to excite the linear structural response for comparison with finite element modal analysis results. The second test was designed to provide data for correlation with crash simulations. A detailed finite element model was developed for execution in MSC.Dytran to generate crash simulations. Following minor modifications, the model was executed in MSC.Nastran to generate modal analysis information.

The results presented in this paper start with existing algorithms such as peak and mean acceleration, DRI, and weighted-averaging (HIC-type) computations. As stated previously, the calculated results are simply and only a means to measure closeness of different types of acceleration time histories. It is clearly understood that the sensitivity of the HIC-type calculation to peak acceleration and duration is defined based on information known about head impacts. Metallic and composite structure will have differing sensitivities to loading and duration and these will most probably be different than that used to develop the HIC.

The following information is a compilation of conclusions and "lessons-learned":

- Extensive analyses of the measured results showed that high quality data from both drop tests of a fuselage section were acquired. The volume of measured data proved valuable for identifying similarities and anomalies in the results. In addition, transducer placement should be based not only for concept evaluation, but also for the correlation with simulations.

- For essentially symmetric positions, the scatter in acceleration time histories was large, nearly $20 \mathrm{~g}$, when compared to the maximum values of $40 \mathrm{~g}$. However, several calculated results, to include mean and peak accelerations and Dynamic Response Index (DRI), indicated that the global variation was significantly less. A major concern was raised as to how to appropriately quantify not only the correlation of test and analysis but also channel-to-channel variations based on the time history and calculated results.

- Frequencies from the finite element modal analysis were within $4 \%$ of the measured values. Sufficient data was available to establish the correlation of mode shapes based on relative phasing.

- Future crash finite element model development could be expedited by correlation with experimental modal analysis results. The accuracy of the modal correlation depends on the accuracy of the global stiffness and mass distribution for the finite element model. In addition, this approach provides a second experimental data set for correlation. This information is particularly 
important in crash applications where traditionally only one data set is acquired since the test specimen is destroyed. In these cases, there exists little opportunity to evaluate data quality for correlation with crash simulations.

- Evaluation of the crash finite element simulation accuracy requires the comparison of results in several formats. Filtered time history accelerations and velocities enable evaluation of correlation details. However, the significant variations between even symmetrically located positions make meaningful quantification of the results difficult to interpret. Several proposed reasons for the discrepancies include: geometric defects, material variations, and inaccurate estimate of the impact conditions.

- Several methods for evaluating the comparison of measured and predicted results were presented. These included peak acceleration, DRI, and weighted-average. These approaches allowed evaluation of the significance of scatter in the time history data in combination with factors such as duration, peak acceleration, onset rate, frequency content, and mean. The methods enable the presentation of all data positions on one figure. Such a presentation can be valuable for evaluating global modeling as well as highlighting both the subtle and pronounced differences between test and analysis.

\section{References:}

1. Vaughan, V. L., Jr.; and Alfaro-Bou, E.: Impact Dynamics Research Facility for Full-Scale Aircraft Crash Testing. NASA TN D-8179, April 1976.

2. Society of Automotive Engineers, Recommended Practice: Instrumentation for Impact Test - Part 1, Electronic Instrumentation, SAE J211/1, March 1995.

3. Fasanella, E. L.; Jackson, K. E.; and Lyle, K. H.: Finite Element Simulation of a Full-Scale Crash Test of a Composite Helicopter. Proceedings of AHS $56^{\text {th }}$ Annual Forum, Virginia Beach, VA, May $2-4,2000$.

4. Bark, L. W.; and Lyle, K. H.: Progress Toward Understanding Correlation of Crash Test with Crash Simulation. Proceedings of the Third International KRASH Users' Seminar, Tempe, AZ, January 8-10, 2001.

5. Stech, E. L., and Payne, P. R.:Dynamic Models of the Human Body. Frost Engineering and Development Corporation, AMRL Technical Report 66-158, Aerospace Medical Research Laboratory, Wright-Patterson AFB, OH, November 1969.

6. Jackson, K. E.; Fasanella, E. L.: Development of a Crashworthy Composite Fuselage Concept. Proceedings of the 2000 Advances in Aviation Safety Conference (P-355), Daytona Beach, FL, April 11-13, 2000. 